\title{
Removal of Levafix Red from Aqueous Solution with Treated Jute Stick and its Relevance to Pharmaceutical Field
}

\author{
Rayhan Hossain, Mohammad Arifur Rahman, Nargish Jahan Ara \\ and A. M. Shafiqul Alam
}

Department of Chemistry, University of Dhaka, Dhaka-1000, Bangladesh

Received: April 12, 2015; Accepted: October 25, 2015; Published (Web): February 17, 2016

\begin{abstract}
The adsorption of levafix red (LR) dye from waste water via batch adsorption onto treated jute stick powder was investigated. Studies concerning the factors influencing the adsorption such as adsorbent dosage, $\mathrm{pH}$, contact time and temperature were systematically investigated and discussed. The results revealed that the maximum removal of levafix red was $\sim 91 \%$ from water. The kinetics data were analyzed using pseudo-first order and pseudo-second order models. It was best described by the pseudo-second order model. The adsorption equilibrium follows Langmuir isotherm. This result indicates that treated jute stick powder could be employed as low-cost alternatives to commercial activated carbon for the removal of levafix red (LR) from waste water. Rapid industrialization in Bangladesh has resulted in increased water pollution that has higher dye level. Waste water from dyeing and finishing factories is a significant source of environmental pollution. The waste water is typically characterized by high levels of COD (chemical oxygen demand) concentration, high concentration of coloring material, large amount of suspended solids, highly fluctuating $\mathrm{pH}$ and high temperature. Dyes may therefore present an ecotoxic hazard and introduces the potential danger of bioaccumulation that may eventually affect man by transport through the food chain. As pharmaceutical industries use lots of water and intake of this type of water might have adverse effects on human health. Therefore, water purification is extremely essential for human and animal health and dye free water may be farther purified for its proper use.
\end{abstract}

Key words: Jute stick, levafix red (LR), adsorption isotherm, adsorption kinetics

\section{Introduction}

Since the end of the last century a large amount of products, such as medicines, laundry detergents, surfactants, pesticides, dyes, paints, preservatives, food additives, have been released by chemical and Pharmaceutical industries threatening the environment and human health. Currently there is a growing awareness of the impact of these contaminants on groundwater, rivers, and lakes. Therefore the removal of these contaminants of concern is now as ever important in the production of safe drinking water and the environmentally responsible release of wastewater (Kümmerer, 2009).
Numerous physiochemical and biological methods have been used to decolorize dye bearing effluents, often in combinations as one single treatment may not be sufficient to remove certain classes of synthetic dyes (Leitch and Armstrong, 2006; Forgacs et al., 2004). Adsorption is considered to be an effective method for the removal of dyes, Pharmaceutical compounds due to the ease of operation and comparable low cost of application (Pereira et al., 2003; Faria et al., 2004). At present, the most commonly used adsorbent in Pharmaceutical and textile wastewater treatment is activated carbon, which has also been studied for the dye removal (Jahan Ara, 2013). But the extensive

Correspondence to: Mohammad Arifur Rahman, E-mail: marahman76@yahoo.com 
application of activated carbon is still in difficulty due to its high cost. Therefore, it is necessary to explore cheaper adsorbent for the removal of dye from wastewater.

Recently, an effect of the salt concentration on the dye sorption was studied in several research works. It was observed a certain increase in the azo dye adsorption onto starch-based polymers in the presence of inorganic salts $(\mathrm{NaCl})$ and explained this phenomenon as a result of the charge reduction on the adsorbent surface (YS Al-Degs et al., 2008). Similarly, the adsorption of reactive (acid) dyes on activated carbon increased in the presence of $\mathrm{NaCl}(0.1-0.5 \mathrm{~mol}$ $1^{-1}$ ) (EY Ozmen et al., 2008). In addition, the presence of $\mathrm{NaCl}$ salt makes a major effect on the range of acidic dyes adsorption by Bentonite adsorbent (Akl et al., 2013). Therefore, the objective of the work is to study the feasibility and potentiality of the $\mathrm{NaCl}$ treated jute stick as bio-adsorbent for the removal of Levafix red (acid dye) (Figure 1) from wastewater.

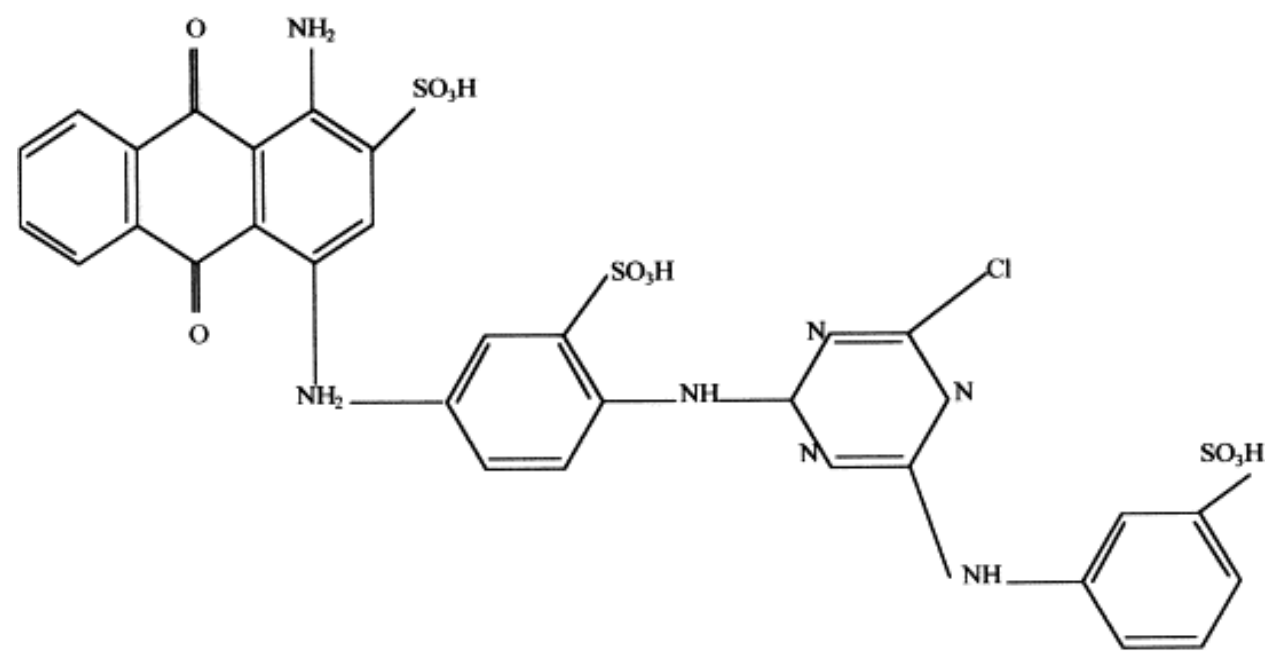

Figure 1. Chemical structure of levafix red.

\section{Experimental}

Preparation of adsorbent: Jute stick was collected from the local market, and then it was cut into small pieces and washed with water to remove any adhering substances and dried at $110^{\circ} \mathrm{C}$. Finally, it was ground into powder. About $2.0 \mathrm{~g}$ of jute stick powder was mixed with $0.5 \mathrm{~g} \mathrm{NaCl}$, and then $25 \mathrm{ml}$ water was added into it. The mixed solution was placed into a shaker for shaking about 1 hour. After shaking it was kept another one hour at room temperature for settlement, and filtered. Then it was heated at $90{ }^{\circ} \mathrm{C}$ in an oven for 6 h for dryness.

Point of zero charge: This is the point where the surface charge of adsorbent is zero. The point of zero charge (PZC) for the treated jute stick powder was determined by the following procedure: $100 \mathrm{ml}$ of deionized water was added to an Erlenmeyer flask, which was then capped with cotton. The deionized water was heated until boiling for $20 \mathrm{~min}$ to eliminate the $\mathrm{CO}_{2}$ and dissolved ions in the water. The $\mathrm{CO}_{2}$ free water was cooled as soon as possible and the flask was immediately capped. Now this water was free from both cations and anions, and it was considered to be neutral water. On the other hand, $0.5 \mathrm{~g}$ of treated jute stick powder was weighed and placed in a $25 \mathrm{ml}$ Erlenmeyer flask to which $10 \mathrm{ml}$ of $\mathrm{CO}_{2}$ free deionized water was added. The flask was sealed with a rubber stopper and left in continuous agitation for $48 \mathrm{~h}$ at $25{ }^{\circ} \mathrm{C}$. The $\mathrm{pH}$ of the solution was measured and this value was the point of zero charge (Jahan Ara, 2013).

Preparation of dye solution: Stock solution of levafix red (LR) was prepared by dissolving the appropriate amount of solid substance in water. $1 \mathrm{~g} \mathrm{LR}$ was taken in a $250.0 \mathrm{ml}$ volumetric flask and it was dissolved by deionized water. Then deionized water 
was added up to the mark to prepare $1000 \mathrm{ppm}$ solution of LR. Further dilution was made whenever necessary. The concentration range used for experiment was 50 $\mathrm{ppm}$ to $250 \mathrm{ppm}$. The required concentration was prepared by dilution.

Study of batch adsorption process: Equilibrium isotherms for adsorption onto the selected carbons determined by using $1 \mathrm{~g}$ of adsorbent per $50 \mathrm{ml}$ of aqueous solution for initial dye concentrations in the range of 50-200 ppm. For the experiment, the bottles were shaken at constant temperature $\left(25^{\circ} \mathrm{C}\right)$ and agitation speed was $(120 \mathrm{rpm})$, for the minimum contact time required to attain equilibrium, as determined from the kinetic measurements. The effectiveness of the treatment was evaluated by measuring concentration by UV-Visible spectroscopic method at $520 \mathrm{~nm}$.

The influence of $\mathrm{pH}$ was studied by adjusting the reaction mixture to different initial $\mathrm{pH}$ values and analyzing the residual color at the equilibrium contact time. The $\mathrm{pH}$ values were adjusted with dilute sulfuric acid and sodium hydroxide solutions. Then the percentage of dye removal was calculated by,

$$
\mathrm{R}=\left[\left(\mathrm{C}_{\mathrm{o}}-\mathrm{C}_{\mathrm{e}}\right) / \mathrm{C}_{\mathrm{o}}\right] \times 100 \%
$$

The amount of dye adsorbed onto the activated carbons, $\mathrm{q}_{\mathrm{e}}(\mathrm{mg} / \mathrm{g})$, was calculated according to:

$$
q_{e}=\frac{\left(C_{0}-C_{e}\right) \times V}{W}
$$

Where $C_{0}$ and $C_{e}$ is the initial and the final dye concentrations (mg/l), respectively and $W$ is the amount of adsorbent ( $\mathrm{g}), \mathrm{V}$ is the volume of the solution ( $\mathrm{L})$.

\section{Results and Discussion}

Physical Properties of the treated jute stick: The physical properties of the jute stick powder have been presented in table 1 . From the table it is found that the BET surface area (Rabolli et al., 2010) was $5.88\left(\mathrm{~m}^{2} / \mathrm{g}\right)$ and the average pore diameter was $99.80 \AA$. The point of zero charge of the prepared activated charcoal was 4.65.
Table 1. Physical properties of treated jute stick powder.

\begin{tabular}{lc}
\hline Properties & Value \\
\hline Particle size & $<140 \mu \mathrm{m}$ \\
BET surface area $\left(\mathrm{m}^{2} / \mathrm{g}\right)$ & 5.886 \\
Average pore diameter $\left(\mathrm{A}^{0}\right)$ & 99.80 \\
Micro pore volume $(\mathrm{cc} / \mathrm{g})$ & 0.023 \\
Micro pore area $\left(\mathrm{m}^{2} / \mathrm{g}\right)$ & 2.17 \\
Bulk density $(\mathrm{g} / \mathrm{ml})$ & 0.89 \\
$\mathrm{pH}$ zpc & 4.65 \\
\hline
\end{tabular}

Surface characterizations: Infra-red (IR) spectra of treated sawdust were measured with Fourier transform infrared spectrometer (Shimadju, Japan) to elucidate the functional group present in jute stick powder. The FTIR spectra of treated jute stick powder as shown in figure 2 exhibited peak at $3400 \mathrm{~cm}^{-1}$, which can be attributed to the stretching of $\mathrm{OH}$ groups. These broad bands indicated high concentration of phenol and alcohol. A greater number of $\mathrm{OH}$ groups of the glucose unit of the cellulose polymers broaden the peak. The peak at 1590 $\mathrm{cm}^{-1}$ was assigned to the $\mathrm{C}=\mathrm{O}$ bonds. The bands at 1116 $\mathrm{cm}^{-1}$ is the contribution from the $\mathrm{C}-\mathrm{H}$ stretching of cellulose and hemicelluloses. The band between 500 and $600 \mathrm{~cm}^{-1}$ shows the presence of the $\mathrm{C}-\mathrm{Cl}$ groups. The $\mathrm{Cl}$ comes from the treatment of Jute stick powder with $\mathrm{NaCl}$ solution.

Scanning electron microscopy (SEM) has been a primary tool for characterizing the surface morphology and fundamental physical properties of the adsorbent. SEM of adsorbent material was taken before and after dye adsorption on activated charcoal is presented in figure 3. From the Figure it was clear, there was a good possibility for dyes to be trapped and adsorbed into these pores. The SEM pictures of adsorbed samples showed very distinguished dark spots which could be taken as a sign for effective adsorption of dye molecules in the cavities and pores of this adsorbent.

Effect of adsorbent dosage: For optimizing the amount of adsorbents, experiments were performed using $50 \mathrm{ml}$ aqueous solution of (levafix red) LR and were shaken for 120 minutes after adding different amount of jute stick powder $(0.5-3.0 \mathrm{~g})$. Absorbance of the filtrate was noted using spectrophotometer at $\lambda$ max of the dye. It was observed that adsorption of the dye 
increased with increase of the amount of adsorbent and then attained constant value at equilibrium as shown in figure 4. Figure 4 shows that about $81 \%$ of dye were removed with $1.5 \mathrm{~g}$ jute stick powder. With increasing the amount of adsorbents (from $0.5 \mathrm{~g}$ to $3.0 \mathrm{~g}$ ) removal efficiency also increased. However, 1.5-3.0 g of adsorbent showed almost the similar removal efficiency with same particle size of $<90 \mu \mathrm{m}$. This was due to the agglomeration of the particles themselves so that the removal efficiency was not significantly increased with amount of adsorbents. Therefore $1.5 \mathrm{~g}$ of adsorbent was chosen for all the subsequent adsorption studies.

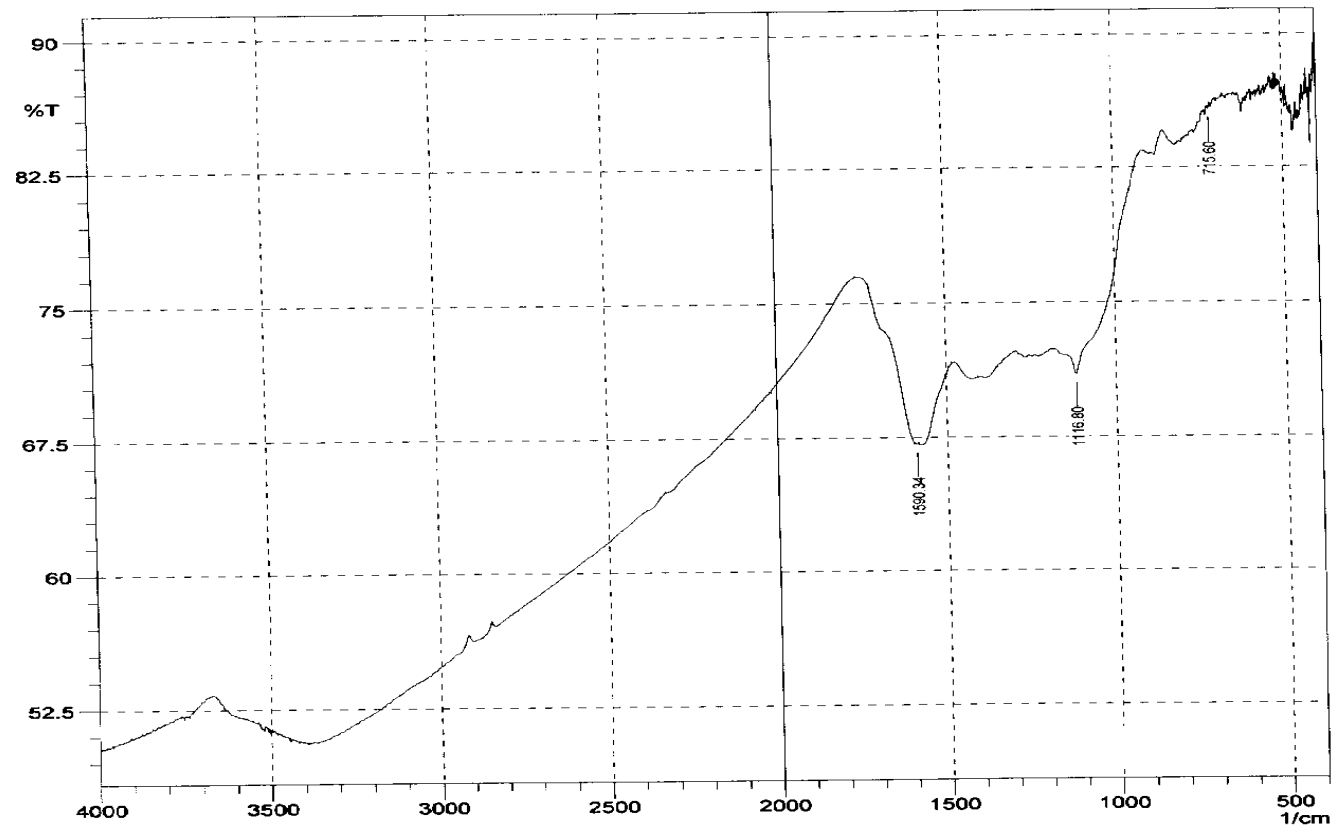

Figure 2. FTIR of treated jute stick powder.
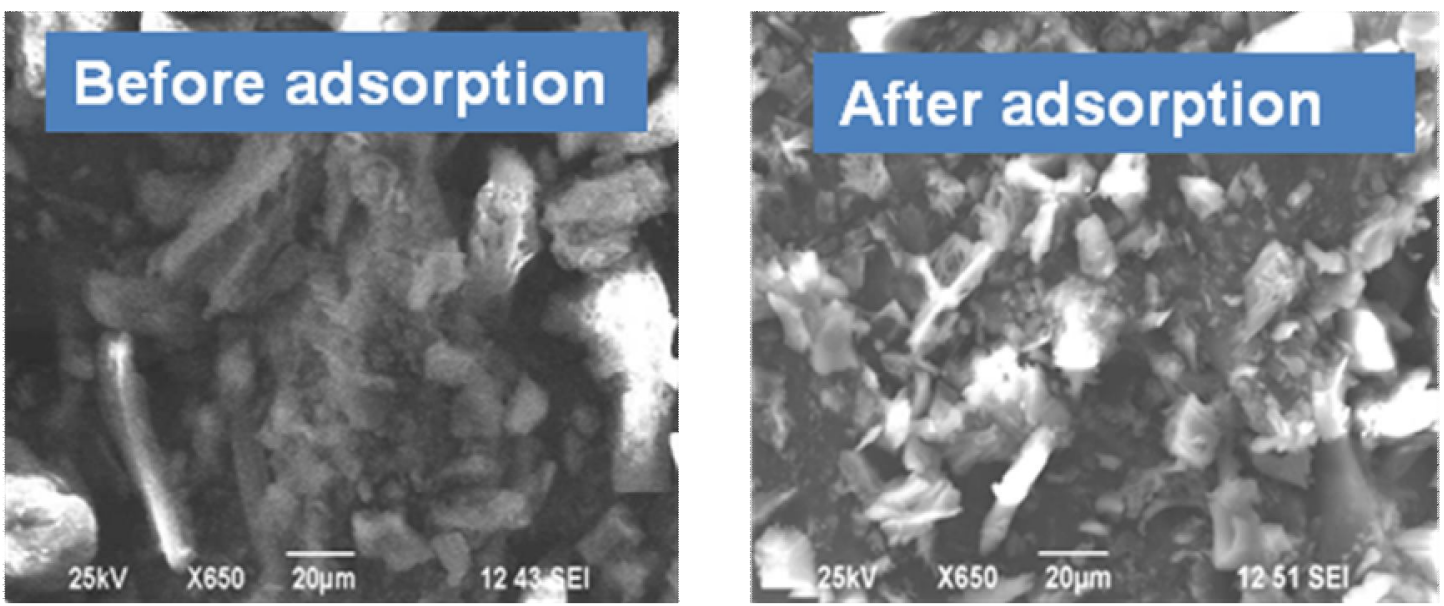

Figure 3. SEM of treated jute sticks before and after adsorption of levafix red dye.

Effect of contact time: The contact time is one of the factors affecting the development of surface charges at the solid solution interface. The effect of period of contact on the removal of levafix red (LR) by the treated jute stick powder was determined by keeping other conditions (initial concentration of the dye, initial volume, $\mathrm{pH}$ and temperature) constant. The effect of contact time was investigated by treating $1.5 \mathrm{~g}$ of the 
jute stick powder with $50 \mathrm{ml}$ of $50 \mathrm{mg} / \mathrm{l} \mathrm{LR}$ solution at $\mathrm{pH}$ value of 7 . The mixture was agitated with mechanical shaker for different periods of contact time $(1-8 \mathrm{~h})$. The results are presented in figure 5 . It was observed that the removal efficiency of LR dye increase in contact time to a certain extent. Further increase in contact time does not increase the uptake due to deposition of dyes on the available adsorption site on adsorbent material. As the data show the adsorption process was rapid for the first $6 \mathrm{~h}$. Therefore $6 \mathrm{~h}$ contact time was chosen for all the subsequent adsorption studies.

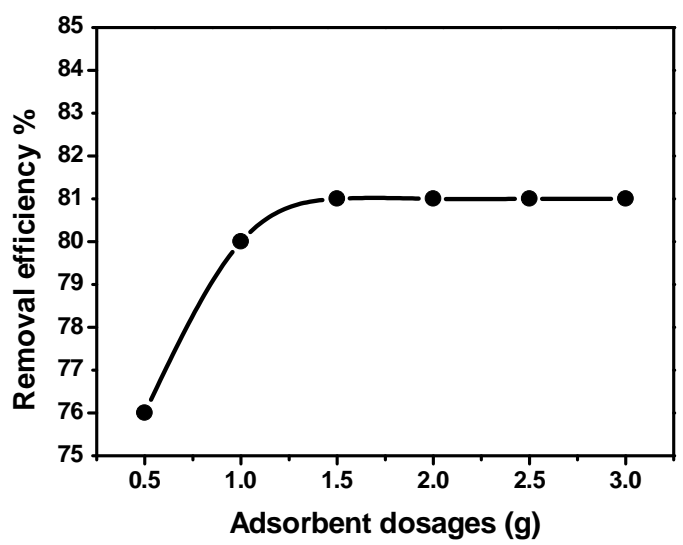

Figure 4. Effect of adsorbent dose for the removal of levafix red. Particle size: $90 \mu \mathrm{m}$; Initial concentration: $50 \mathrm{mg} / \mathrm{l}$ Initial volume: $25 \mathrm{ml}$; $\mathrm{pH}$ : 4.0; Contact time: 5 hours; Temp.: $25^{\circ} \mathrm{C}$.

Effect of $p H$ : In the present work, the pHzpc (zero point charge) of the jute stick powder was found to be 4.65. At a $\mathrm{pH}$ of solution below the pHzpc of the adsorbent, the surface of the treated jute stick powder is positively charged and can attract anions from the solution. When $\mathrm{pH}$ of the solution is less than $\mathrm{pHzpc}$, the surface of the treated jute stick powder is positively charged and attractive to anions (Sharma et al., 2009; Sun et al., 2007). In this study, the effect of $\mathrm{pH}$ on the percentage of removal of Levafix Red (LR) dye using jute stick powder was evaluated as shown in figure 6 . To investigate the effect of $\mathrm{pH}$, the experiment of adsorption of dye solution was carried out at different $\mathrm{pH}$ value (2.0-12.0) by using $0.01 \mathrm{M} \mathrm{HCl}$ and $0.01 \mathrm{M}$ $\mathrm{NaOH}$ aqueous solution. It could be seen that as the $\mathrm{pH}$ increased the adsorption of dye decreases. The maximum uptake was observed at the $\mathrm{pH}$ range 2.03.0. At $\mathrm{pH}$ below 4.6 the attributed electrostatic interactions between the positively charged of jute stick powder and the negatively charged of LR dye prefer to give the LR percentage removal (93\%). Since $\mathrm{pH} 2.0$ was highly acidic condition therefore $\mathrm{pH} 3.0$ was selected for optimized condition for further adsorption study.

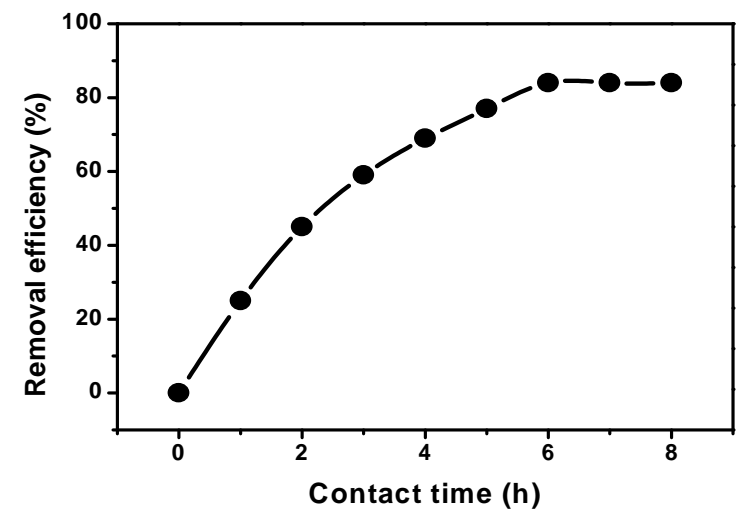

Figure 5. Effect of contact time for the removal of levafix red. Particle size: $90 \mu \mathrm{m}$; Initial concentration: $50 \mathrm{mg} / \mathrm{l}$ Initial volume: $25 \mathrm{ml}$; $\mathrm{pH}$ : 4.0 ; Temp.: $25^{\circ} \mathrm{C}$.

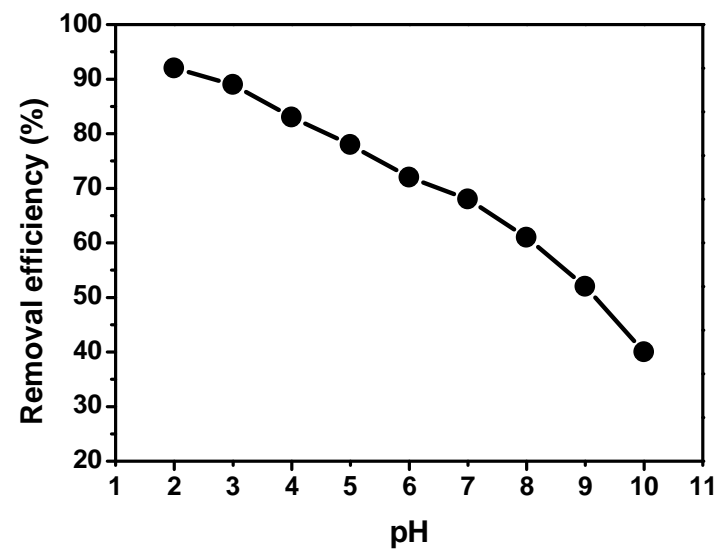

Figure 6. Effect of $\mathrm{pH}$ for the removal of levafix red. Particle size: $90 \mu \mathrm{m}$; Initial concentration: $50 \mathrm{mg} / \mathrm{l}$ Initial volume: $25 \mathrm{ml}$; Temp.: $25^{\circ} \mathrm{C}$ Contact time: $6 \mathrm{~h}$.

Effect of temperature: Temperature is an important parameter affecting the bio-sorption process as various dye effluents are discharged at relatively high temperature. To determine the equilibrium temperature for the maximum uptake of dye solution (LR), the adsorption onto jute stick powder was studied for the above optimized condition as a function of temperature $\left(25-40{ }^{\circ} \mathrm{C}\right)$ is presented in figure 7 . Figure 7 , indicates that the removal efficiency decreases gradually with increasing temperature from $25{ }^{\circ} \mathrm{C}$ to $40{ }^{\circ} \mathrm{C}$. As the 
temperature increase, rate of diffusion of adsorbate molecules across the external boundary layer and interval pores of the adsorbent particle increase (Waranusantigul et al., 2003). This may be the cause of increased dye adsorption of jute stick at low temperature. But the adsorption was decreased at higher temperature due to increase of interval pores which induce diffusion and reduce levafix red (LR) dye retention.

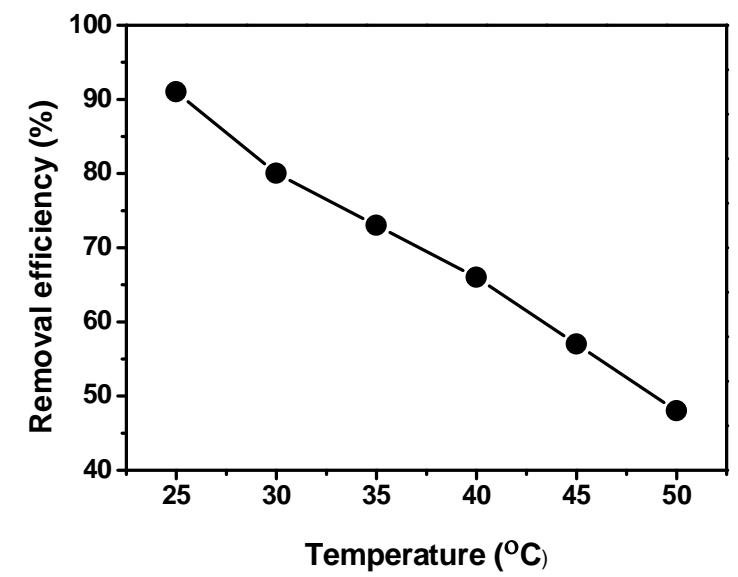

Figure 7. Effect of temperature for the removal of levafix red. Particle size: $90 \mu \mathrm{m}$; Initial concentration: $50 \mathrm{mg} / \mathrm{l}$ Initial volume: $25 \mathrm{ml}$; $\mathrm{pH}$ : 3; Contact time: $6 \mathrm{~h}$.

Adsorption isotherm: The adsorption isotherm used to show the adsorption molecules distribute between the solid phase and liquid phase at adsorption equilibrium state. The Langmuir and Freundlich isotherms are the most frequently employed models. The linear regression is used to determine the best-fitting isotherm and the pertinences of isotherm equations is compared by evaluating the correlation coefficients, $R^{2}$. Langmuir's isotherm model is based on the theory that adsorption energy is constant and uptake occurs on homogeneous surface by monolayer adsorption. When the surface is covered by monolayer of adsorbate, the adsorption goes on localized sites with no interaction between adsorbate molecules and that maximum adsorption occurs (Langmuir, 1918). The linear form of Langmuir isotherm equation is given as:

$\frac{C_{e}}{q_{e}}=\frac{1}{q_{m} K_{a}}+\frac{C_{e}}{q_{m}}$

Where, $C_{e}(\mathrm{mg} / \mathrm{l})$ is the Levafix Red (LR) equilibrium concentration and $\mathrm{q}_{\mathrm{e}}(\mathrm{mg} / \mathrm{g})$ is the amount of LR adsorbed per unit mass of adsorbent. $\mathrm{q}_{\mathrm{m}}(\mathrm{mg} / \mathrm{g})$ is the Langmuir constant related to adsorption capacity and $K_{a}(1 / m g)$ is rate of adsorption. The values of $q_{m}$ and $\mathrm{K}_{\mathrm{a}}$ were calculated from the intercept and slope of linear plot and are presented in figure 8 .

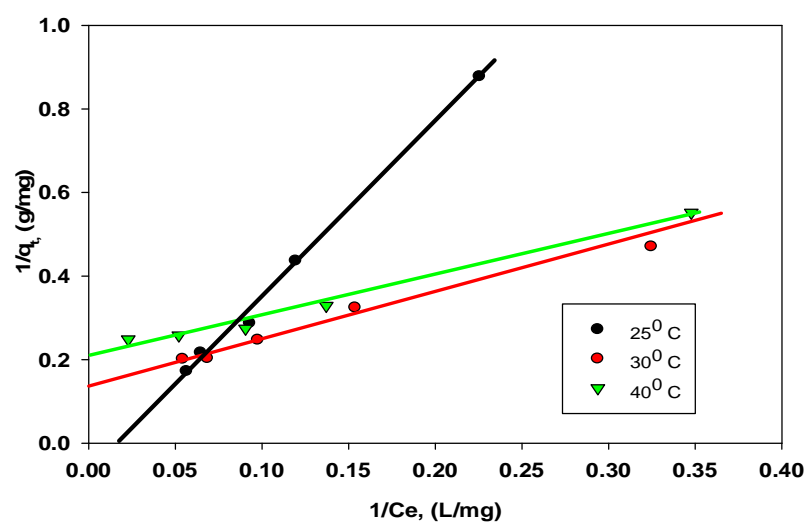

Figure 8. Langmuir plots for the adsorption of levafix red on treated jute sticks.

Freundilch model (Freundlich, 1906) is an empirical expression that is the earliest known relationship describing the adsorption equation. This isotherm takes into account a heterogeneous surface and multilayer adsorption to the binding sites on the surface of the adsorbent. The Freundlich model is expressed in the following equation:

$$
\log \left(q_{e}\right)=\frac{1}{n} \log \left(C_{e}\right)+\log \left(K_{F}\right)
$$

Where, $\mathrm{K}_{\mathrm{F}}$ and $\mathrm{n}$ are indicative isotherm parameters of adsorption capacity and adsorption intensity, respectively. Generally, $\mathrm{n}>1$ illustrates that adsorbate is favorably adsorbed on the adsorbent. The higher the number of $\mathrm{n}$, the more favorable the adsorption and stronger the adsorption intensity (Ahmad and Alrozi, 2011). From the Freundilch and Langmuir plot, the isotherm results are presented in figure 8 and 9 . From the table 2, it was found that Langmuir model gave higher $\mathrm{R}^{2}$ values (0.996) than Freundlich model (0.986), which indicate that LR adsorption by jute stick powder was made up of heterogeneous surface and multilayer adsorption (Özcan et al., 2007). This result is similar to other works on reactive dye adsorption by activated carbon prepared from coir pith (Santhy and Selvapathy, 2006). For all the experiments, the value of ' $n$ ' is greater than 
one which indicates good adsorption of LR onto treated jute stick powder.

Adsorption kinetics: Kinetics adsorption data of LR dye on treated jute stick powder was analyzed using two kinetic models: pseudo-first-order and pseudosecond order. The pseudo-first-order kinetic model is shown by the following equation (Ho et al., 2005):

$$
\log \left(\mathrm{q}_{\mathrm{e}}-\mathrm{q}_{\mathrm{t}}\right)=\log \mathrm{q}_{\mathrm{e}}-\frac{k_{1}}{2.303} t
$$

Where, $\mathrm{q}_{\mathrm{t}}$ is the amount of dye adsorbed at time $\mathrm{t}$ $\left(\mathrm{mgg}^{-1}\right), \mathrm{q}_{\mathrm{e}}$ is the amount adsorbed at equilibrium $(\mathrm{mg} / \mathrm{g}), \mathrm{k}_{1}$ is the pseudo-first order rate constant $\left(\mathrm{min}^{-1}\right)$ and $t$ is the contact time (min).

The values of the constants, $\mathrm{k}_{1}$ and $\mathrm{q}_{\mathrm{e}}$ for the adsorption of dye on the adsorbents were determined from the slopes and intercepts of the plots $\log \left(q_{e}-q_{t}\right)$ against $\mathrm{t}$ in figure 10 and their values are given in table 3. Pseudo-second order model can be represented in the following form (Ho and Mckay, 1999):

$$
\frac{t}{q e}=\frac{1}{k_{2} q_{e}^{2}}+\frac{1}{q_{e}} t
$$

Where, $\mathrm{k}_{2}$ is the Pseudo-second order rate constant $\left(\mathrm{gmg}^{-1} \mathrm{~min}^{-1}\right)$. The values of the $\mathrm{q}_{\mathrm{e}}$ and $\mathrm{k}_{2}$ were determined by plotting a graph between $t / q_{t}$ and time in figure 11 . The applicability of the pseudo first order and pseudo second order model can be examined by linear plots. The linearity of this plot indicates the applicability of the two models. However the correlation coefficient, $\mathrm{R}^{2}$ shows that second order model fits the experimental data better than the pseudo first order model (Table 3).

Table 2. Freundlich and Langmuir parameters for levafix red on treated jute stick powder.

\begin{tabular}{cccccc}
\hline \multicolumn{3}{c}{ Freundlich isotherm } & \multicolumn{3}{c}{ Langmuir isotherm } \\
\hline $\mathrm{K}_{\mathrm{F}}$ & $\mathrm{N}$ & $\mathrm{R}^{2}$ & $\mathrm{q}_{\mathrm{m}}$ & $\mathrm{K}_{\mathrm{L}}$ & $\mathrm{R}^{2}$ \\
\hline 1.221 & 1.996 & 0.986 & 6.788 & 0.144 & 0.996 \\
\hline
\end{tabular}

Table 3. Kinetic parameters for the adsorption of levafix red on jute stick powder.

\begin{tabular}{ccccccc}
\hline $\begin{array}{c}\text { Pseudo first order Kinetic model } \\
\text { qe }\end{array}$ & $\begin{array}{c}\text { qe exp. } \\
\mathrm{mg} / \mathrm{g}\end{array}$ & \multicolumn{2}{|l}{ Pseudo second order Kinetic model } \\
\hline 1.82 & 0.838 & 0.975 & 2.64 & 2.85 & 0.634 & 0.996 \\
\hline
\end{tabular}

Table 4. Removal of levafix red from the waste water by the developed method.

\begin{tabular}{llcc}
\hline Sample No. & Adsorbent & Concentration & Removal efficiency\% \\
\hline S1 & Treated jute stick & 50 & 82.62 \\
& Jute stick & 50 & 70.12 \\
S2 & Treated jute stick & 50 & 83.47 \\
& Jute stick & 50 & 71.38 \\
S3 & Treated jute stick & 50 & 83.26 \\
& Jute stick & 50 & 71.80 \\
\hline
\end{tabular}

Desorption: After completing the adsorption the residue was dried in air and then used to investigate desorption. Desorption studies shows that the amount of desorption increases with time. This also indicates that desorption is physical in nature, which is consistent with thermodynamic study. Desorption studies help to elucidate the nature of adsorption and recycling of the spent adsorbent and the dyes. If the adsorbed dyes can be desorbed using neutral $\mathrm{pH}$ water, then the attachment of the dyes on the adsorbent is weak. If 
sulphuric acid or alkaline water desorbs the dyes, then the adsorption is by ion exchange. If organic acids, like acetic acid desorb the dyes, then the dye is attached to the adsorbent through chemisorption. The effect of various reagents used for desorption studies shows that sodium hydroxide is a better reagent for desorption, because we could get more than $90 \%$ removal of adsorbed dyes. The reversibility of adsorbed dyes in mineral acid or base is in agreement with the $\mathrm{pH}$ dependent results obtained. Desorption of dyes by mineral acids and alkaline medium indicates that the dyes are adsorbed onto the treated jute sticks by physisorption.

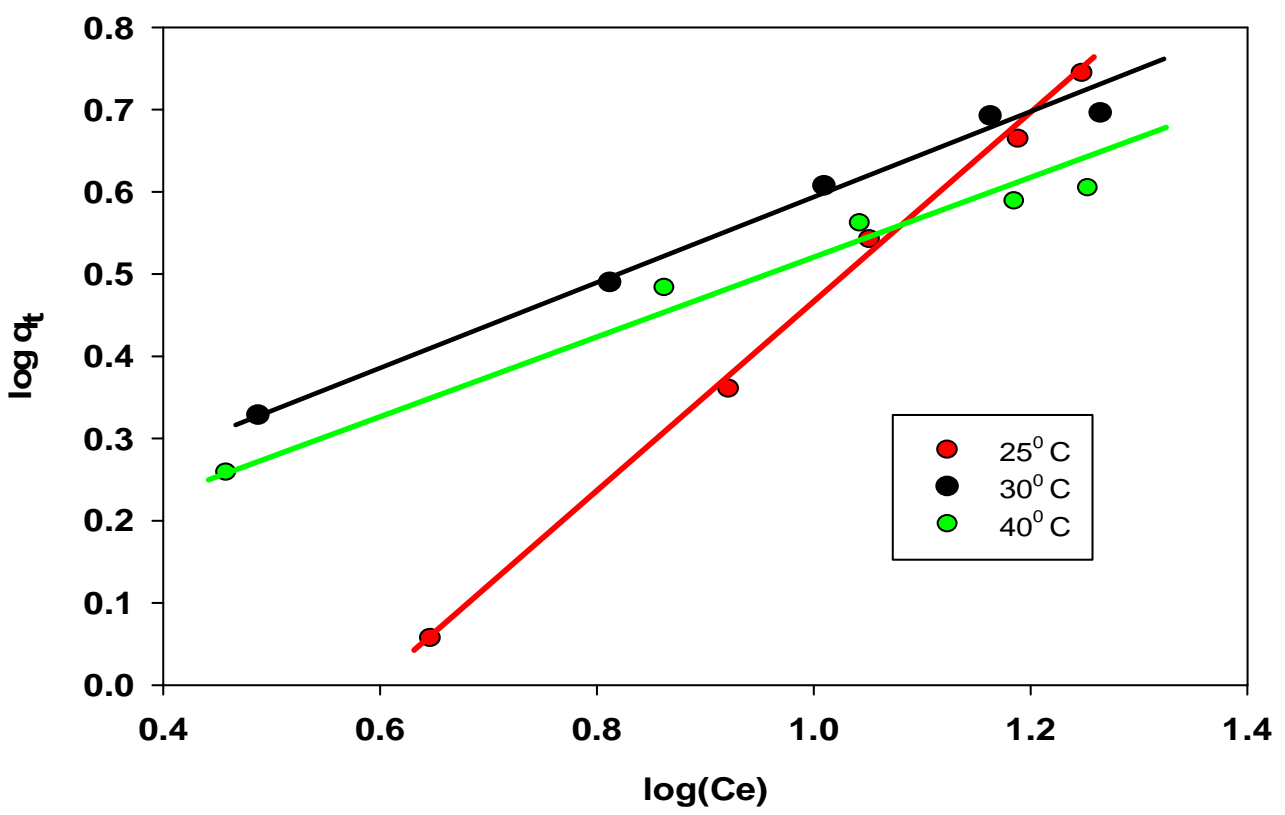

Figure 9. Freundlich plots for the adsorption of levafix red on treated jute sticks.

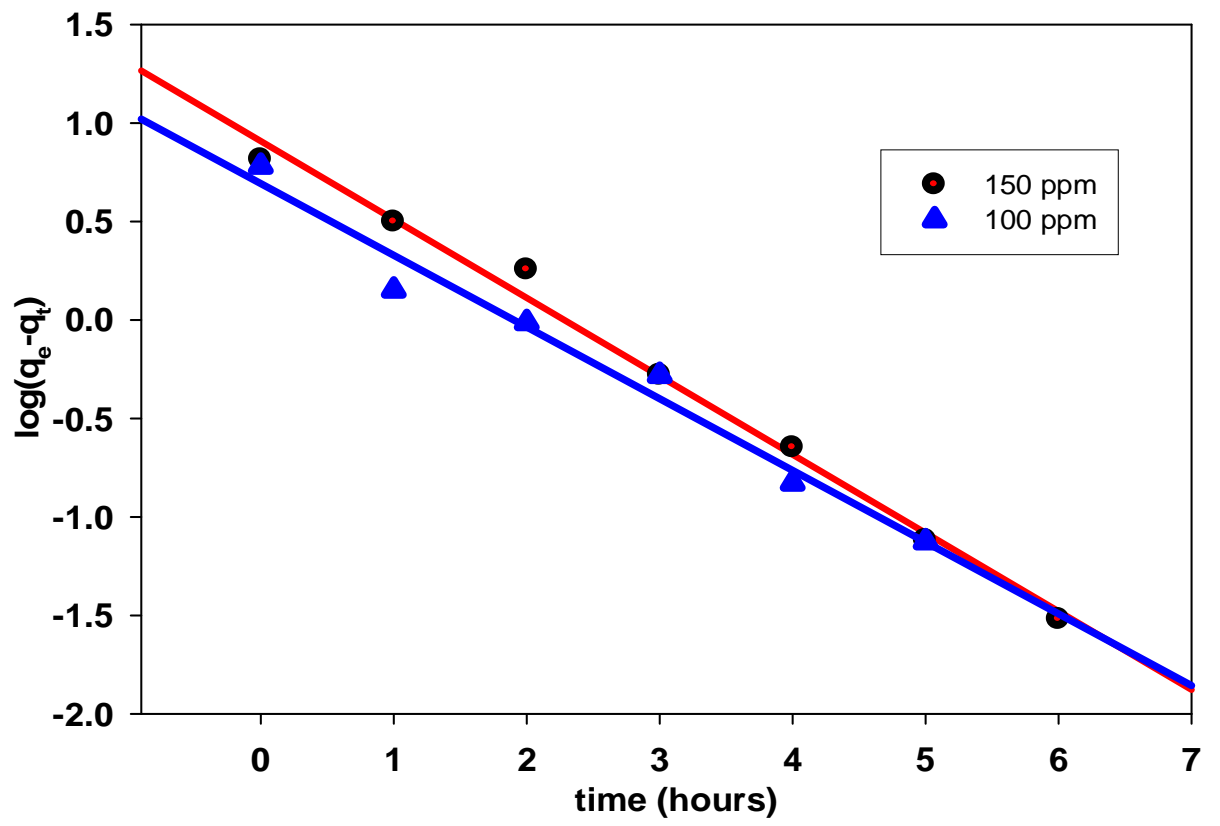

Figure 10. Pseudo first order kinetic model plots. 


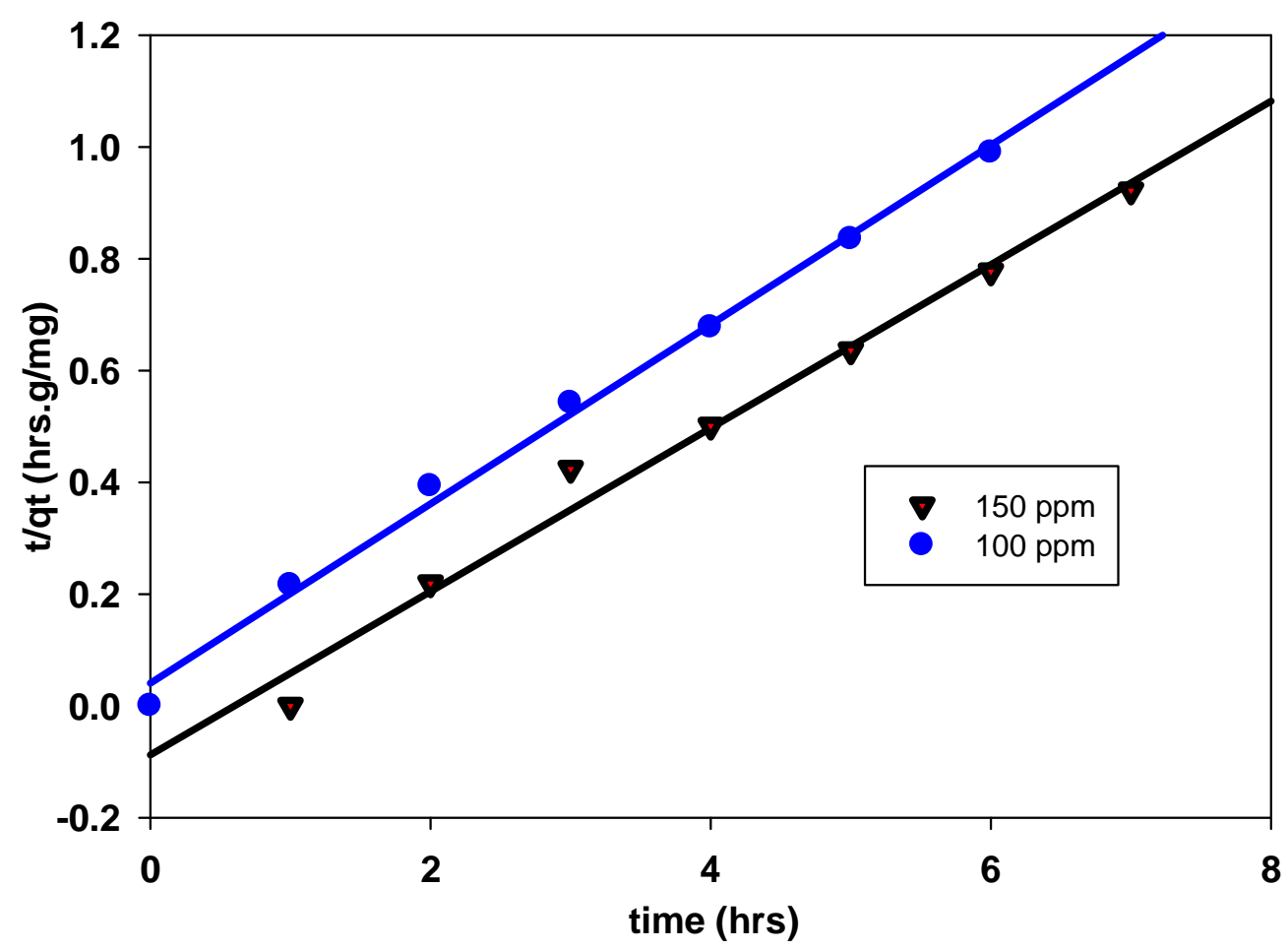

Figure 11. Pseudo second order kinetic model plots.

Application of the developed treatment system to industrial waste water (Real Sample): The utility of the treated jute sticks was evaluated for the treatment of Levafix red contaminated waste water samples. The concentration of total Levafix red in the samples was 50 ppm. As the $\mathrm{pH}$ of the water samples were around 11.33. The treatment results are presented in (Table 4). $3.0 \mathrm{~g}$ of adsorbent was applied in the treatment. The $\mathrm{pH}$ of the solution is lowered to 3.0 by adding $0.001 \mathrm{M} \mathrm{HCl}$ solution. From the present results, the Levafix red was successfully removed from industrial waste water.

Probable removal mechanism: The maximum removal percentages of levafix red (LR) dye was at acidic $\mathrm{pH}$ (3.0) and decreased gradually with increasing in $\mathrm{pH}$. The protonated groups in jute stick powder were mainly carboxylic group $\left(-\mathrm{CO}-\mathrm{OH}^{2+}\right)$, phenolic $\left(-\mathrm{OH}^{2+)}\right.$ and chromenic groups. Levafix red is an anionic dye (acid dye). It dissociated anions into the solution. The de-protonated groups of levafix red dyes were probably the sulphonate groups $\left(-\mathrm{SO}_{3}{ }^{-}\right)$. Generally, electrostatic interaction between positively charged groups of jute stick powder and negatively charged dye molecules was the main force controlling the adsorption process. In the $\mathrm{pH}$ range of $>4.6$, the surface of jute stick powder was negatively charged ( $\mathrm{pHzpc}=4.6)$ and Levafix dyes were positively charged because of the sulphonate groups of the dye were almost protonated $\left(\mathrm{SO}_{3} \mathrm{H}\right)$. The low percentage of dye removal at highly basic solution could be due to the strong repulsion interaction between the negatively charged jute stick powder surfaces and the protonated LR dye molecules. At the same time, hydroxide ion concentration increased with the incremental solution $\mathrm{pH}$, and it could be adsorbed preferentially on the surface of the jute stick powder. There was competition between $\mathrm{OH}^{-}$(at high $\mathrm{pH}$ ) and dye ions for positively charged adsorption sites. These results could be decreased evidently the removal efficiency of levafix red dyes. The treatment of $\mathrm{NaCl}$ on jute stick facilitates the dye adsorption effectively. This can be attributed to an increase in dimerization of dyes in solution in contact with $\mathrm{NaCl}$ salt by the aggregation of dye molecules (Alberghina $\mathrm{G}$ et al., 2000). These forces include: vander waals forces; ion-dipole forces; and dipole-dipole forces, which occur between the dye in solution induced by the action of $\mathrm{NaCl}$ salt ions. 


\section{Conclusion}

This study was performed using treated jute stick powder for the removal of levafix red dye solution at laboratory conditions. The optimized conditions were applied for real sample collected from Tongi industrial area, Dhaka, Bangladesh. However, removal efficiency of the levafix red dye with the optimized conditions was low. The real samples are in fact complicated because textile industries use a mixture of various types of dyes for different applications. Research in this regard is being continued. Treated jute stick removed the levafix red more significantly then untreated jute stick from waste water. Jute stick bio-sorbents are biodegradable, environmental friendly and non toxic. Therefore, treated jute stick can be a low cost and effective way to reduce water pollution from industrial wastewater. These studies can further ameliorate the economic aspects of dye wastewater treatment which will get better opportunity for the water related pollution remediation in Pharmaceutical industries.

\section{References}

Ahmad, M.A. and R. Alrozi, 2011. Removal of malachite green dye from aqueous solution using rambutan peelbased activated carbon: equilibrium, kinetic and thermodynamic studies. Chem. Eng. J. 171, 510-516.

Akl, M.A., Youssef, A.M. and Al-Awadhi, M.M. 2013. adsorption of acid dyes onto Bentonite and Surfactantmodified Bentonite. J. Anal. Bioanal. Tech. 4, 172-174.

Alberghina, G., Bianchini, R., Fichera, M. and Fisichella, S. 2000. Dimerization of Cibacron blue F3GA and other dyes: influence of salts and temperature. Dyes and Pigments 46, 129-137.
Al-Degs, Y.S., El-Barghouthi, M.I., El-Sheik, A.H. and Walker, G.M. 2008. Effect of solution pH, ionic strength and temperature on adsorption behavior of reactive dyes on activated carbon. Dyes and Pigments 77, 16-25.

Faria, P.C.C., Orfao, J.J.M. and Pererira, M.F.R. 2004. Adsorption of anionic and cationic dyes on activated carbons with different surface chemistries. Water Res. 38, 2043-2052.

Forgacs, E., Cserhati, T. and Oros, G. 2004. Removal of synthetic dyes from waste waters: a review. Environ Int. 30, 953-971.

Freundlich, H.M.F. 1906. Over the adsorption in solution. $J$. Physical Chem. 385, 385-470.

Ho, Y.S., Chiu, W.T. and Wang, C.C. 2005. Regression analysis for the sorption isotherms of basic dyes on sugarcane dust. Bioresour. Technol. 96, 1285-1291.

Ho, Y.S. and McKay, G. 1999, Pseudo-second order model for sorption processes. Process Biochem. 34, 451-465.

Jahan Ara, N., Hasan, M.A., Rahman, M.A., Salam, M.A., Salam, A. and Alam, A.M.S. 2013. Removal of remazol red from textile waste water using treated sawdust-an effective way of effluent treatment. Bangladesh Pharma. J. 16, 93-98.

Kümmerer, K. 2009. The presence of pharmaceuticals in the environment due to human use - present knowledge and future challenges. J. Environ. Manage. 90, 2354-2366.

Langmuir, I. 1918. The adsorption of gases on plane surfaces of glass, mica and platinum. J. American Chem. Society 40, 1361-1403.

Leitch, A.E., Armstrong, P.B. and Chu, K.H. 2006. Characteristics of dye adsorption by pretreated pine bark adsorbents. Int. J. Environ. Stud. 63, 59-66.

Özcan, A., Ömeroğlu, Č., Erdoğan, Y. and Özcan, A.S. 2007. Modification of bentonite with a cationic surfactant: an adsorption study of textile dye reactive blue 19. J. Hazard. Mater. 140, 173-179. 